\title{
Body mass index, sitting time, and risk of Parkinson disease
}

Elin Roos, MD, Alessandra Grotta, MSc, PhD, Fei Yang, MD, PhD, Rino Bellocco, MSc, PhD, Weimin Ye, MD, PhD, Hans-Olov Adami, MD, PhD, Karin Wirdefeldt, MD, PhD, and Ylva Trolle Lagerros, MD, PhD

Neurology ${ }^{\circledR}$ 2018;90:e1413-e1417. doi:10.1212/WNL.0000000000005328

\section{Abstract}

\section{Objective}

Causes of Parkinson disease are largely unknown, but recent evidence suggests associations with physical activity and anthropometric measures.

\section{Methods}

We prospectively analyzed a cohort of 41,638 Swedish men and women by detailed assessment of lifestyle factors at baseline in 1997. Complete follow-up until 2010 was achieved through linkage to population-based registers. We used multivariable Cox proportional hazards models to estimate hazard ratios with $95 \%$ confidence intervals (CIs).

\section{Results}

We identified 286 incident cases of Parkinson disease during follow-up. Multivariable adjusted hazard ratios were 1.06 (95\% CI $0.76-1.47$ ) for sitting time $\geq 6$ vs $<6$ hours per day; and 1.13 (95\% CI $0.60-2.12$ ) for body mass index $\geq 30 \mathrm{vs}<25 \mathrm{~kg} / \mathrm{m}^{2}$. Results did not differ by sex.

\section{Conclusions}

No association between prolonged sitting time per day or obesity and risk of Parkinson disease was found.

\author{
Correspondence \\ Dr. Trolle Lagerros \\ ylva.trolle@ki.se
}

From the Department of Medicine (E.R., Y.T.L.), Unit of Clinical Epidemiology, Karolinska Institutet, T2, Stockholm; Department of Medical Epidemiology and Biostatistics (A.G., F.Y., R.B., W.Y., H.-O.A., K.W.), and Department of Clinical Neuroscience (K.W.), Karolinska Institutet, Stockholm; Centre for Health Equity Studies (A.G.), Stockholm University/Karolinska Institutet, Stockholm, Sweden; Department of Statistics and Quantitative Methods (R.B.), University of Milano-Bicocca, Milan, Italy; Clinical Effectiveness Research Group (H.-O.A.), Institute of Health and Society, University of Oslo, Norway; and Department of Medicine (Y.T.L.), Clinic of Endocrinology, Metabolism and Diabetes, Karolinska University Hospital, Stockholm, Sweden.

Go to Neurology.org/N for full disclosures. Funding information and disclosures deemed relevant by the authors, if any, are provided at the end of the article.

The Article Processing Charge was funded by Swedish Research Council for Health, Working Life and Welfare.

This is an open access article distributed under the terms of the Creative Commons Attribution License 4.0 (CC BY), which permits unrestricted use, distribution, and reproduction in any medium, provided the original work is properly cited. 


\section{Glossary}

BMI = body mass index; $\mathbf{C I}=$ confidence interval; $\mathbf{I C D}$ = International Classification of Diseases; PD = Parkinson disease.

The etiology of Parkinson disease (PD) is unknown. Environmental ${ }^{1}$ and lifestyle factors including body mass index (BMI) are discussed in the context of PD causation. ${ }^{2}$ By decreasing dopamine receptor availability, obesity may increase the risk of PD. ${ }^{3}$

We recently reported that higher household and commute physical activity lowers the risk of PD. ${ }^{4}$ Regardless of time spent on physical activity, sedentary behavior characterized by sitting extended periods of time has been associated with increased general morbidity and mortality. ${ }^{5}$ Thus, sedentary behavior may affect PD pathogenesis through mechanisms other than physical activity. No previous study has, however, examined sitting time and the risk of developing PD. We therefore studied BMI and sitting time in a large cohort of Swedish men and women with a 13-year follow-up and detailed adjustment for physical activity and other potential confounders.

\section{Methods}

\section{Study population}

The Swedish National March Cohort comprises 43,863 Swedish participants who, at a national fund-raising event in September 1997, completed a comprehensive questionnaire with extensive assessment of lifestyle factors. ${ }^{6}$ Exposure data were collected for smoking, alcohol intake, height and weight, as well as education level. We also assessed physical activity and sedentary behavior using a questionnaire specially developed and validated for this study. ${ }^{7}$

All participants provided their individually unique national registration number, enabling identification of health status through linkage of medical records to Swedish populationbased registers. Participants who lacked a valid registration number $(\mathrm{n}=11)$, emigrated, died, had a PD diagnosis before start of follow-up $(n=482)$, or who were younger than 18 years $(n=1,732)$ were excluded. In total, 41,638 participants were finally included in the study.

Participants were followed from October 1, 1997, until a primary or secondary diagnosis of $\mathrm{PD}$, emigration, death, or until end of follow-up on December 31, 2010, whichever occurred first. Index date of diagnosis was defined as first-ever outpatient contact or hospital discharge with a diagnosis of PD from the Swedish Patient Register. The Swedish revisions of the ICD codes for PD were used: 350 (ICD-7, 1964-1968), 342 (ICD-8, 1969-1986), 332A (ICD-9, 1987-1996), and G20 (ICD-10, 1997-2010).

\section{Statistical methods}

Height and weight were self-reported in the questionnaire and BMI was calculated by dividing reported weight $(\mathrm{kg})$ by the squared height $\left(\mathrm{m}^{2}\right)$. BMI was categorized according to the standard classification of the World Health Organization into underweight or normal weight $\left(<25 \mathrm{~kg} / \mathrm{m}^{2}\right)$, overweight $(\geq 25$ to $\left.<30 \mathrm{~kg} / \mathrm{m}^{2}\right)$, and obesity $\left(\geq 30 \mathrm{~kg} / \mathrm{m}^{2}\right)$. Because few individuals were underweight $(\mathrm{n}=579)$, we categorized both underweight and normal weight as "normal weight." Sitting time was characterized by bathing, listening to music, watching television, office work, knitting, and sewing and categorized into either less or more than 6 hours of sitting per day.

We first assessed the baseline characteristics of the study participants for the entire cohort and stratified by BMI and sitting time. We computed age-standardized incidence rates for PD in each category of BMI and sitting time. Direct standardization was implemented using the 5-year age categories distribution of follow-up person-years of the entire cohort.

A Cox proportional hazards regression model was fitted to estimate hazard ratios and corresponding $95 \%$ confidence intervals (CIs) of PD at various levels of BMI and sitting time, using age as the underlying time scale. We initially adjusted for sex. Then we further adjusted for the following potential confounders: smoking status (never, former, current), alcohol consumption $(<73.3, \geq 73.3$ to $<314.8$, or $\geq 314.8 \mathrm{~g} / \mathrm{mo}$ ), coffee intake (never, low [1-2 cups/d], medium [3-4 cups/d], or high $[\geq 5$ cups/d]), and educational level ( $\leq 13$ or $>13$ years), and waist circumference categorized into standardized categories for women $(<80$, $\geq 80$ to $<88$, or $\geq 88 \mathrm{~cm})$ and men $(<94, \geq 94$ to $<102$, or $\geq 102$ $\mathrm{cm})$, according to the International Diabetes Federation consensus and the World Health Organization. Participants reported how many hours per week they spent on household activities, such as working in the garden, cleaning the house or commuting, such as walking or biking to work. We were therefore able to further adjust for household and commuting physical activity $(\leq 2,3-4,5-6,>6 \mathrm{~h} / \mathrm{wk})$ as our finding in a previous study showed an inverse association with this type of physical activity and risk of PD. ${ }^{4}$

We assessed a linear trend across categories of BMI and sitting time by including the median values of each category of BMI and sitting time in the model as a continuous variable. We also repeated the analyses stratified by sex, smoking status (never, ever), and age at baseline $(<65, \geq 65$ years). We used the deviance test based on scaled Schoenfeld residuals to assess the proportional hazards assumption and ran stratified Cox regression models when the assumption was not satisfied. Finally, we performed 3 sensitivity analyses. First, we excluded the first 2, then 3 , and then 5 years of follow-up to avoid reverse causation 
bias. In the second one, we also included PD cases identified through the Cause of Death Register. In a third sensitivity analysis, we used multiple imputation models based on chained equations ${ }^{8}$ under the assumption of data missing at random to assess the robustness of the observed findings. We imputed missing values only for the confounders.

The proportion of missing data on the exposure variables was $4.6 \%$ for BMI, and $2.0 \%$ for sitting time. Percentages of

Table 1 Baseline characteristics of participants in the Swedish National March Cohort, categorized by sitting time and body mass index

\begin{tabular}{|c|c|c|c|c|c|c|}
\hline & \multirow[b]{2}{*}{ All } & \multicolumn{2}{|c|}{ Sitting time, $\mathrm{h} / \mathrm{d}$} & \multicolumn{3}{|c|}{ Body mass index, $\mathrm{kg} / \mathrm{m}^{2}$} \\
\hline & & $<6$ & $\geq 6$ & $<25$ & 25 to $<30$ & $\geq 30$ \\
\hline No. of participants & 41,638 & 26,960 & 13,834 & 23,776 & 13,054 & 2,907 \\
\hline Male, \% & 35.8 & 37.2 & 33.1 & 32.1 & 44.4 & 28.7 \\
\hline Age, y, mean (SD) & $51.6(16.1)$ & $52.9(16.7)$ & $48.5(14.2)$ & $49.5(16.8)$ & $55.0(14.2)$ & $52.9(14.0$ \\
\hline Height, cm, mean (SD) & $170.1(8.8)$ & $170.0(8.8)$ & $170.4(8.9)$ & $170.1(8.7)$ & $170.7(9.0)$ & $167.9(9.2$ \\
\hline Weight, kg, mean (SD) & $71.5(12.5)$ & $71.5(12.4)$ & 71.5 (12.9) & $65.0(8.7)$ & $78.5(9.1)$ & $92.4(12.6$ \\
\hline \multicolumn{7}{|l|}{ Waist circumference, \% } \\
\hline Low $^{a}$ & 37.33 & 36.78 & 39.06 & 56.36 & 15.28 & 1.65 \\
\hline Medium $^{\mathrm{b}}$ & 59.45 & 22.64 & 21.43 & 18.82 & 34.14 & 7.12 \\
\hline High $^{c}$ & 75.37 & 16.06 & 15.80 & 3.52 & 29.32 & 65.43 \\
\hline \multicolumn{7}{|c|}{ Household/commuting physical activity, h/wk, \% } \\
\hline$\leq 2$ & 15.44 & 13.18 & 19.86 & 13.78 & 15.86 & 23.63 \\
\hline $3-4$ & 29.48 & 28.04 & 32.54 & 28.58 & 30.85 & 31.03 \\
\hline $5-6$ & 21.97 & 22.16 & 21.69 & 22.90 & 21.46 & 19.33 \\
\hline$>6$ & 32.59 & 36.12 & 25.58 & 34.29 & 31.42 & 25.52 \\
\hline \multicolumn{7}{|l|}{ Smoking, \% } \\
\hline No & 59.2 & 59.8 & 57.8 & 62.0 & 55.4 & 54.2 \\
\hline Former & 25.2 & 24.5 & 27.3 & 22.9 & 29.3 & 30.9 \\
\hline Current & 7.1 & 6.7 & 8.1 & 7.7 & 6.1 & 7.3 \\
\hline \multicolumn{7}{|l|}{ Alcohol, g/mo, \% } \\
\hline$<73.3$ & 33.2 & 36.0 & 26.8 & 32.6 & 31.9 & 40.8 \\
\hline$\geq 73.3$ to $<314.8$ & 33.3 & 32.9 & 34.5 & 34.4 & 31.8 & 31.5 \\
\hline$\geq 314.8$ & 33.3 & 30.8 & 38.6 & 32.9 & 36.1 & 27.4 \\
\hline \multicolumn{7}{|c|}{ Coffee consumption, cups/d, \% } \\
\hline 0 & 11.9 & 11.3 & 13.5 & 14.3 & 8.2 & 10.5 \\
\hline $1-2$ & 29.4 & 29.8 & 28.7 & 31.0 & 27.5 & 25.2 \\
\hline $3-4$ & 40.0 & 40.4 & 39.0 & 38.3 & 42.6 & 42.2 \\
\hline$\geq 5$ & 16.9 & 16.6 & 17.4 & 14.7 & 20.1 & 20.6 \\
\hline \multicolumn{7}{|l|}{ Education, $y, \%$} \\
\hline$\leq 13$ & 70.5 & 74.4 & 62.3 & 66.9 & 74.6 & 77.3 \\
\hline$>13$ & 27.5 & 23.5 & 36.1 & 31.2 & 23.7 & 21.1 \\
\hline
\end{tabular}

a $<94 \mathrm{~cm}$ for men and $<80 \mathrm{~cm}$ for women.

b $94-102 \mathrm{~cm}$ for men and $80-88 \mathrm{~cm}$ for women.

c $>102 \mathrm{~cm}$ for men and $>88 \mathrm{~cm}$ for women. 
missing values on confounders were all below $2 \%$, except for smoking and waist circumference, which were missing for $8.4 \%$ and $24.6 \%$ of the study participants, respectively.

The $p$ values $<0.05$ were considered statistically significant. All statistical analyses were performed with Stata version 14 (StataCorp LP, College Station, TX).

\section{Standard protocol approvals, registrations, and patient consents}

The research ethics board in Stockholm approved the study and all subjects gave informed consent.

\section{Results}

Participants' characteristics are presented in table 1. Participants who were obese had a lower educational level compared to both normal and overweight participants. Those who sat 6 or more hours per day were more likely to be ever smokers, high consumers of alcohol, and to have a higher educational level compared to participants who sat less than 6 hours a day.

We identified 286 incident cases of PD during 159 months of follow-up. We found no significant association between baseline BMI, sitting time, and risk of PD, or any evidence of trend (table 2). Age- and sex-adjusted analyses provided results similar to our multivariable adjusted results presented in table 2 (results not shown). In these analyses, sitting time of 6 or more hours per day compared with less than 6 hours per day increased risk of PD by $6 \%$ (95\% CI $-24 \%$ to $47 \%$ ), and BMI of 30 or higher compared with BMI less than 25 increased risk of PD by $13 \%$ (95\% CI $-40 \%$ to $112 \%$ ). When we stratified the analyses for sex, smoking status (ever-never), and age at baseline (cutoff 65 years), the results were similar in men and women. The results from the sensitivity analyses did not differ significantly (results not shown).

\section{Discussion}

In this prospective cohort study, we found no association between sitting time or BMI and risk of PD. Associations between sedentary behavior and vascular diseases, depression, and impaired cognitive function have been described. ${ }^{5}$ Studies examining the relationship between sitting time and PD risk are rare. Palacios et al. ${ }^{9}$ reported no relationship between BMI and PD. Our findings are in line with both Palacios et al. and a recent quantitative review showing no evidence that high $\mathrm{BMI}$ increases the risk of PD. ${ }^{10}$

Strengths of our study include its prospective design, complete long-term follow-up, inclusion of both men and women, and extensive adjustment for potential confounders. The limited statistical power of the study undermines its ability to establish weak associations. Like many other epidemiologic studies, we relied on self-reported information for body measures potentially inducing misclassification. Such misclassification would be nondifferential and lead to an attenuation of the association given our prospective study design. Also, validation studies of self-reported weight and height have shown that BMI values calculated from self-reports have a high sensitivity in classifying someone as overweight or obese. ${ }^{11,12}$

Nevertheless, anthropometric measures as well as sitting time might have changed during follow-up. If such changes are related to the outcome, this could lead to misclassification and an over- or underestimation of any true association. Still, if PD development begins many years before symptom onset, this places the exposure window of interest closer to the baseline exposure assessment. Repeated exposure assessments closer

Table 2 Age-standardized IRs and multivariable-adjusted HRs with 95\% Cls of Parkinson disease for body mass index and sitting time in the Swedish National March Cohort

\begin{tabular}{|c|c|c|c|c|c|}
\hline \multirow[b]{2}{*}{ Multivariable adjusted $^{a}$} & \multicolumn{4}{|c|}{ Parkinson disease } & \multirow[b]{2}{*}{$p$ Trend } \\
\hline & No. & IR & HR & $95 \% \mathrm{Cl}$ & \\
\hline Sitting time, $\mathrm{h} / \mathrm{d}$ & & & & & 0.727 \\
\hline$<6$ & 145 & 7.12 & 1.00 & Ref. & \\
\hline$\geq 6$ & 53 & 11.51 & 1.06 & $0.76-1.47$ & \\
\hline Body mass index, $\mathrm{kg} / \mathrm{m}^{2}$ & & & & & 0.849 \\
\hline$<25$ & 108 & 7.79 & 1.00 & Ref. & \\
\hline$<30$ & 74 & 6.75 & 0.96 & $0.68-1.38$ & \\
\hline$\geq 30$ & 16 & 6.86 & 1.13 & $0.60-2.12$ & \\
\hline
\end{tabular}

Abbreviations: $\mathrm{Cl}=$ confidence interval; $\mathrm{HR}=$ hazard ratio; $\mathrm{IR}=$ incidence rate; Ref. = reference.

IR presented per 10,000 person-years. No. = number of participants with Parkinson disease after excluding participants with missing values on at least one of the covariates included in the model.

a Adjusted for age (model time scale), sex, education, smoking, alcohol consumption, body mass index, waist circumference, sitting time, and household and commute physical activity. 
to the end of follow-up might increase the risk of reverse causation.

The diagnosis of PD was obtained from the Swedish Inpatient Register and although the accuracy is good, ${ }^{13}$ misclassification between $\mathrm{PD}$ and other parkinsonian disorders might have occurred, and information on the relative severity at time of diagnosis and symptom onset is not available in the Inpatient Register.

Our findings indicate that sitting time and BMI are not associated with PD risk. Future studies should focus on environmental factors other than obesity and sedentary time in efforts to disentangle the complex causation of PD.

\section{Author contributions}

Elin Roos: study concept and design, interpretation of data, writing of the first draft. Alessandra Grotta: study concept and design, statistical analysis, writing of the first draft. Fei Yang: study concept and design, critical revision of manuscript for intellectual content. Rino Bellocco: statistical analysis, critical revision of manuscript for intellectual content. Weimin Ye: acquisition of data, critical revision of manuscript for intellectual content. Hans-Olov Adami: study concept and design, acquisition of data, critical revision of manuscript for intellectual content. Karin Wirdefeldt: study concept and design, critical revision of manuscript for intellectual content. Ylva Trolle Lagerros: study concept and design, acquisition of data, interpretation of data, critical revision of manuscript for intellectual content.

\section{Study funding}

Funded by the regional agreement on medical training and clinical research between Stockholm County Council and Karolinska Institutet for Y.T.L. K.W. received research grants from the Swedish Research Council for Health, Working Life and Welfare, Karolinska Institutet, the Parkinson Foundation in Sweden, and the Parkinson Research Foundation in Sweden, and H.-O.A. received the Karolinska Institutet Distinguished Professor Award (Dnr: 2368/10-221).

\section{Disclosure}

The authors report no disclosures relevant to the manuscript. Go to Neurology.org/N for full disclosures.

Received August 4, 2017. Accepted in final form January 17, 2018.

\section{References}

1. Kamel F. Epidemiology: paths from pesticides to Parkinson's. Science 2013;341: $722-723$.

2. Wirdefeldt K, Adami HO, Cole P, Trichopoulos D, Mandel J. Epidemiology and etiology of Parkinson's disease: a review of the evidence. Eur J Epidemiol 2011;26 (suppl 1):S1-S58.

3. Wang GJ, Volkow ND, Logan J, et al. Brain dopamine and obesity. Lancet 2001;357: 354-357.

4. Yang F, Trolle Lagerros Y, Bellocco R, et al. Physical activity and risk of Parkinson's disease in the Swedish National March Cohort. Brain 2015;138:269-275.

5. Patel AV, Bernstein L, Deka A, et al. Leisure time spent sitting in relation to total mortality in a prospective cohort of US adults. Am J Epidemiol 2010;172: 419-429.

6. Trolle Lagerros Y, Hantikainen E, Mariosa D, et al. Cohort profile: the Swedish National March Cohort. Int J Epidemiol 2017;46:795e.

7. Lagerros YT, Mucci LA, Bellocco R, Nyren O, Balter O, Balter KA. Validity and reliability of self-reported total energy expenditure using a novel instrument. Eur J Epidemiol 2006;21:227-236.

8. Royston P. Multiple imputation of missing values. Stata J 2004;4:227-241.

9. Palacios N, Gao X, McCullough ML, et al. Obesity, diabetes, and risk of Parkinson's disease. Mov Disord 2011;26:2253-2259.

10. Wang YL, Wang YT, Li JF, Zhang YZ, Yin HL, Han B. Body mass index and risk of Parkinson's disease: a dose-response meta-analysis of prospective studies. PLoS One 2015; 10:e131778.

11. Craig BM, Adams AK. Accuracy of body mass index categories based on self-reported height and weight among women in the United States. Matern Child Health J 2009; 13:489-496.

12. Lin CJ, DeRoo LA, Jacobs SR, Sandler DP. Accuracy and reliability of self-reported weight and height in the Sister Study. Public Health Nutr 2012;15:989-999.

13. Feldman AL, Johansson AL, Gatz M, et al. Accuracy and sensitivity of parkinsonian disorder diagnoses in two Swedish national health registers. Neuroepidemiology 2012;38:186-193. 


\section{Body mass index, sitting time, and risk of Parkinson disease}

Elin Roos, MD, Alessandra Grotta, MSc, PhD, Fei Yang, MD, PhD, Rino Bellocco, MSc, PhD, Weimin Ye, MD, PhD, Hans-Olov Adami, MD, PhD, Karin Wirdefeldt, MD, PhD, and Ylva Trolle Lagerros, MD, PhD

Cite as: Neurology ${ }^{\circledR}$ 2018;90:e1413-e1417. doi:10.1212/WNL.0000000000005328
Correspondence

Dr. Lagerros

ylva.trolle@ki.se

\section{Study question}

Are body mass index (BMI) and hours of sitting per day risk factors for Parkinson's disease (PD)?

\section{Summary answer}

Neither is a risk factor for PD.

\section{What is known and what this paper adds}

Studies have reported that greater physical activity levels lower PD risk. However, this study provides evidence contradicting the hypothesis that sedentary behavior and obesity increase PD risk.

\section{Participants and setting}

This study analyzed data for 41,638 Swedish participants (35.8\% male; mean age at enrolment, $51.6 \pm 16.1$ years).

\section{Design, size, and duration}

Participants completed a comprehensive questionnaire in September 1997 that asked about lifestyle factors including height and weight, which were used to calculate baseline BMIs, and time spent on various activities throughout the day, which was used to estimate baseline daily sitting time. A BMI of $<25$ $\mathrm{kg} / \mathrm{m}^{2}$ represented normal weight; a BMI of $\geq 25$ to $<30 \mathrm{~kg} / \mathrm{m}^{2}$, overweight; and a BMI of $\geq 30 \mathrm{~kg} / \mathrm{m}^{2}$, obesity. The study accessed Swedish medical registries for participants' data from 1 October 1997 until a primary or secondary PD diagnosis, emigration, death, or 31 December 2010, whichever came first. PD diagnoses were identified by searching for relevant International Classification of Diseases codes.

\section{Main results and the role of chance}

The study identified 286 incident PD cases over 159 months of follow-up. A Cox proportional hazards regression model with multivariable adjustments showed that a baseline BMI indicative of overweight or obesity was not
Table Cox proportional hazards regression analysis of risk factors for incident PD

\begin{tabular}{lll}
\hline & $\begin{array}{l}\text { Adjusted hazard ratio } \\
\text { for developing PD }\end{array}$ & $\begin{array}{l}\text { 95\% confidence } \\
\text { interval }\end{array}$ \\
\hline $\begin{array}{l}\text { Sitting time } \\
\geq 6 \text { h/d vs }<6 \text { h/d }\end{array}$ & 1.06 & $0.76-1.47$ \\
\hline $\begin{array}{l}\text { Overweight vs } \\
\text { normal BMI }\end{array}$ & 0.96 & $0.68-1.38$ \\
\hline $\begin{array}{l}\text { Obese vs normal } \\
\text { BMI }\end{array}$ & 1.13 & $0.60-2.12$ \\
\hline
\end{tabular}

associated with increased PD risk compared to a normal baseline BMI ( $p$ for trend $=0.849$ ). The same was true for an estimated baseline daily sitting time $\geq 6$ hours compared to an estimated baseline daily sitting time $<6$ hours ( $p$ for trend $=0.727)$.

\section{Bias, confounding, and other reasons for caution}

This study relied on self-reported baseline data that might not have been representative of the entire follow-up period.

\section{Generalizability to other populations}

This study examined a very large cohort, which favors the generalizability of the results.

\section{Study funding/potential competing interests}

This study was funded by Stockholm County Council; the Swedish Research Council for Health, Working Life and Welfare; the Parkinson Foundation in Sweden; and the Parkinson Research Foundation in Sweden. The authors report no competing interests. Go to Neurology.org/ $\mathrm{N}$ for full disclosures. 


\title{
Neurology
}

\author{
Body mass index, sitting time, and risk of Parkinson disease \\ Elin Roos, Alessandra Grotta, Fei Yang, et al. \\ Neurology 2018;90;e1413-e1417 Published Online before print March 21, 2018 \\ DOI 10.1212/WNL.0000000000005328
}

This information is current as of March 21, 2018

\begin{tabular}{|c|c|}
\hline $\begin{array}{l}\text { Updated Information \& } \\
\text { Services }\end{array}$ & $\begin{array}{l}\text { including high resolution figures, can be found at: } \\
\text { http://n.neurology.org/content/90/16/e1413. full }\end{array}$ \\
\hline References & $\begin{array}{l}\text { This article cites } 13 \text { articles, } 1 \text { of which you can access for free at: } \\
\text { http://n.neurology.org/content/90/16/e1413.full\#ref-list-1 }\end{array}$ \\
\hline Citations & $\begin{array}{l}\text { This article has been cited by } 1 \text { HighWire-hosted articles: } \\
\text { http://n.neurology.org/content/90/16/e1413.full\#\#therarticles }\end{array}$ \\
\hline Subspecialty Collections & $\begin{array}{l}\text { This article, along with others on similar topics, appears in the } \\
\text { following collection(s): } \\
\text { Parkinson's disease/Parkinsonism } \\
\text { http://n.neurology.org/cgi/collection/parkinsons_disease_parkinsonism }\end{array}$ \\
\hline Permissions \& Licensing & $\begin{array}{l}\text { Information about reproducing this article in parts (figures,tables) or in } \\
\text { its entirety can be found online at: } \\
\text { http://www.neurology.org/about/about_the_journal\#permissions }\end{array}$ \\
\hline Reprints & $\begin{array}{l}\text { Information about ordering reprints can be found online: } \\
\text { http://n.neurology.org/subscribers/advertise }\end{array}$ \\
\hline
\end{tabular}

Neurology ${ }^{\circledR}$ is the official journal of the American Academy of Neurology. Published continuously since 1951, it is now a weekly with 48 issues per year. Copyright Copyright ( 2018 The Author(s). Published by Wolters Kluwer Health, Inc. on behalf of the American Academy of Neurology. All rights reserved. Print ISSN: 0028-3878. Online ISSN: 1526-632X.

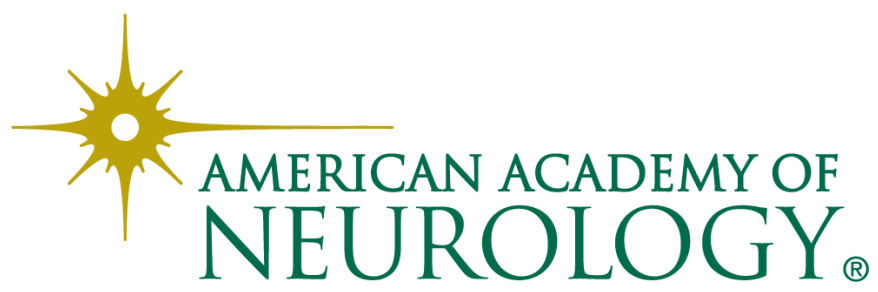

